\title{
PENGARUH METODE DRILL TERHADAP HASIL SMASH SISWA EKSTRAKULIKULER PERMAINAN BULUTANGKIS SMK NEGERI 1 LEMAHABANG KECAMATAN LEMAHABANG KABUPATEN CIREBON
}

\author{
Safitri $^{1}$ dan Endi Rustandi ${ }^{2}$ \\ Universitas Majalengka, Indonesia \\ ariyanisafitri87@gmail.com
}

\begin{abstract}
ABSTRAK. Penelitian ini dilakukan untuk mengetahui pengaruh metode drill terhadap hasil smash siswa ekstrakulikuler permainan bulutangkis SMK Negeri 1 Lemahabang Kecamatan Lemahabang Kabupaten Cirebon. Dimana siswa ekstrakulikuler permainan bulutangkis proses latihannya cenderung belum bervariasi atau kurang efektif, metode yang diberikan kbelum bervariasi sehingga metode drill dalam permainan bulutangkis belum digunkan. Sehingga masih ada beberapa siswa yang kurang baik dalam melakukan smash permainan bulutangkis. Penelitian ini menggunakan pendekatan kuantitatif dengan metode eksperimen (eksperiment) dengan desain one groups pretest posttest desigen. Dalam desain ini terdapat pretest sebelum diberikan perlakuan dan posttest setelah diberikan perlakuan dengan sempel dalam penelitian ini berjumlah 20 siswa, 9 putri dan 11 putra. Berdasarkan hasil analisis penelitian menunujukan bahwa ada pengaruh yang signifikan metode drill berpengaruh untuk hasil smash siswa ekstrakulikuler permainan bulutangkis SMK Negeri 1 Lemahabang Kecamatan Lemahabang Kabupaten Cirebon. Hasil smash pretest mendapatkan nilai minimal 30, nilai maksimal 46, rata-rata 36.80 dengan standar deviasi 4.420. siswa yang telah mendapatkan perlakuan dengan metode drill hasil latihan meningkat dengan hasil smash posttest mendapatkan nilai minimal 34, nilai maksimal 48, rata-rata 42.30 dengan standar deviasi 3.962.
\end{abstract}

Kata Kunci: Metode Drill; Hasil Smash; Permainan Bulutangkis

\section{Pendahuluan}

Bulutangkis merupakan salah satu cabang olahraga permainan yang diminati hampir di berbagai penjuru dunia, dikarenakan bulutangkis dapat dimainkan oleh berbagai kelompok umur. Dari anak-anak, pemula, remaja, dewasa bahkan orang tua pun masih banyak yang memilih cabang olahraga bulutangkis sebagai olahraga untuk menjaga dan mempertahankan kebugarannya, sehingga banyak kejuaraan yang diadakan setiap tahunnya untuk ajang penyaluran bakat dan prestasi atlet-atlet disetiap daearah. Perkembangan perbulutangkisan di Indonesia berkembang sangat pesat. Banyak klub yang bermunculan di hampir setiap daerah di Indonesia.Selain pelatnas, pusdiklat dan klub pembinaan juga dilakukan di sekolah melalui kegiatan ekstrakulikuler.

Bermain bulutangkis tidak hanya mengutamakan teknik permaianan saja, tetapi juga menyangkut sikap, posisi, serta langkah kaki yang tepat sebagai dasar sebelum memulai aksi dilapangan. Sikap dan posisi berdiri di lapangan harus sedemikian rupa, sehingga berat badan tetap berada pada kedua kaki dan tetap menjaga keseimbangan tubuh. Dengan sikap yang 
sempurna dan baik itu dapat secara cepat bergerak kesegala penjuru lapangan permaianan. Footwork atau langkah kaki merupakan dasar untuk bisa menghasilkan pukulan berkualitas yaitu apabila dilakukan dalam posisi baik. Untuk bisa memukul dengan posisi yang baik, seorang siswa harus memiliki kecepatan gerak. Kecepatan gerak kaki tidak bisa dicapai kalau footwork tidak teratur.

Untuk menjadi seorang pemain bulutangkis juga harus menguasai teknik dasar, salah satunya smash. Pukulan smash menentukan dalam mendapat angka. Smash yakni pukulan overhead (pukulan di atas kepala) yang diarahkan ke bawah dan dilakukan dengan tenaga penuh. Pukulan ini identik sebagai pukulan menyerang. Tujuan utamanya adalah mematikan lawan. Pukulan smash adalah bentuk pukulan keras yang sering digunakan dalam permainan bulutangkis.

Berdasarkan observasi, di SMK Negeri 1 Lemahabang, bahwa proses latihan yang cenderung belum bervariasi atau kurang efektif, sehingga masih ada beberapa siswa yang kurang baik dalam melakukan smash, kemampuan siswa dalam melakukan smash masih sangat bervariatif, ada siswa yang sudah bisa bisa melakukan dengan baik dan ada juga siswa yang masih kurang dalam menguasai keterampilan smash. Siswa dalam melakukan teknik smash masih salah, sehingga perkenaan shuttlecock menyangkut di net dan bahkan keluar lapangan.

Smash merupakan salah satu teknik pukulan dalam permainan bulutangkis. Untuk memiliki pukulan smash yang baik dibutuhkan latihan yang teratur. Salah satu untuk mendapatkan poin atau angka yaitu smash. Salah satu metode latihan yang digunakan adalah metode drill. Metode drill merupakan cara latihan smash dengan menggunakan gerakan yang diulang-ulang. Maka dari pada itu peneliti ingin membuat suatu metode drill seperti memberikan servis panjang pada siswa dan siswa melakukan smash. Sasaran ditunjukan dari kanan ke posisi kiri lawan dan sasaran dari kiri ke posisi kanan lawan. Sehingga siswa melakukan smash setelah diberi umpan oleh pelatih atau guru dengan servis panjang. Dengan gerakan yang diulang-ulang tentunya untuk meningkatkan kembali keinginan dan kemampuan siswa dalam melakukan teknik-teknik dasar gerakan smash pada permainan bulutangkis dilakukan tidak terasa berat, dan secara menyeluruh dapat meningkatkan prestasi ekstrakulikuler bulutangkis disekolah.

Berdasarkan latar belakang diatas untuk menindak lanjuti hal perlu diketahui kemampuan dari masing-masing siswa ekstrakulikuler bulutangkis di SMK Negeri 1 Lemahabang. Dengan demikian, peneliti tertarik untuk meneliti secara ilmiah melalui penelitian skripsi dengan judul "Pengaruh Metode Drill Terhadap Hasil Smash Siswa Ekstrakulikuler Permainan Bulutangkis SMK Negeri 1 Lemahabang Kecamatan Lemahabang 
Kabupaten Cirebon". Kemudian dengan adanya penelitian ini diharapkan dapat memberikan masukan kepada pelatih bulutangkis agar dapat mengoptimalkan metode latihan yang tepat untuk menunjang prestasi di ekstrakulikuler bulutangkis, sehingga penelitian ini perlu dilakukan.

\section{Metode Penelitian (12 pt)}

Metode penelitian ini adalah penelitian ekperimen pendekatan kuantitatif. Penelitian eksperimen adalah penelitian yang dilakukan secara ketat untuk mengetahui hubungan sebab akibat diantara variabel. Adapaun pendekatan kuantitatifnya adalah menekankan analisisnya pada data-data numerical (angka-angka) yang di olah dengan metode statistic. Dengan metode kuantitatif akan diperoleh signifikansi perbedaan kelompok atau signifikansi hubungan antar variabel yang diteliti (Badriah, 2012). Desain penelitian yang digunakan adalah "one groups pretest posttest design", yaitu desain penelitian yang terdapat Pretest sebelum diberikan perlakuandan Posttest setelah diberikan perlakuan, dengan demikian dapat diketahui lebih akurat, karena dapat membandingkan dengan diadakan sebelum diberi perlakuan (Sugiyono, 2017:110).

Populasi dalam penelitian ini adalah siswa ekstrakulikuler bulutangkis yang berjumlah 20 orang. Teknik sampling merupakan teknik pengambilan sampel Sugiono (2017). Teknik sampling dalam penelitian ini dengan menggunakan teknik total sampling dengan jumlah sampel yaitu seluruh siswa ekstrakulikuler permainan bulutangkis, siswa SMK Negeri 1 Lemahabang sebanyak 9 putri dan 11 putra total sampel 20 orang.

Pengumpulan data dalam penelitian ini adalah dengan tes pengukuran ketepatan smash bulutangkis yang telah di tetapkan PB PBSI 2006 (Wiratama, 2016) adapun prosedur pelaksanaan tes smash adalah sebagai berikut :

a. Alat yang digunakan antara lain: lapangan bulutangkis, net, raket, shuttlecock, meteran, dan formulir pencatat hasil lengkap dengan alat tulis yang dibutuhkan.

b. Petugas terdiri dari tiga orang, yaitu satu orang pemanggil, satu orang pencatat hasil smash, dan satu orang pelaksana servis.

c. Pelaksanaan tes

Testee mula-mula mengambil sikap siap normal dengan posisi yang sudah ditentukan sambil memegang raket. Setelah mendengar aba-aba "siap" dan "ya" lalu testee melompat dengan raket diayunkan ke atas, dan kemudian melakukan smash yang di drill oleh pengumpan sebanyak 10 kali pukulan. 
d. Skor

Hasil yang dicatat adalah angka yang dihasilakan testee dalam melakukan tes keterampilan smash sebanyak 10 kali kesempatan. Jika shuttlecock keluar dari lapangan permainan atau tidak melewati net maka bernilai nol.

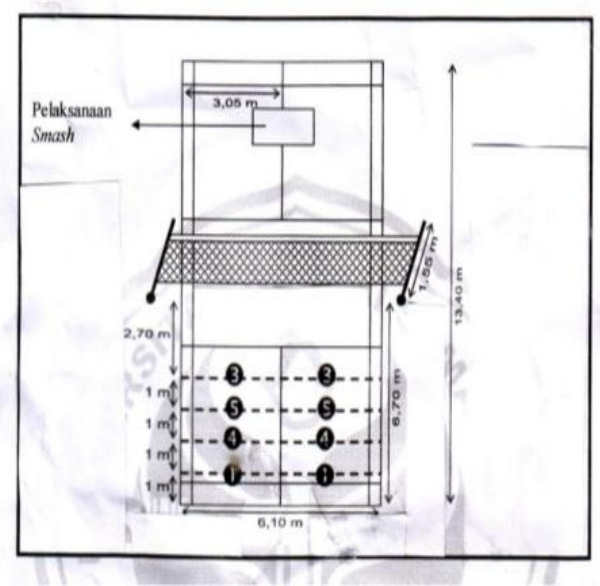

Gambar 1

Lapangan Tes keterampilan Smash Bulutangkis Sumber: PB PBSI, 2006 (dalam Wiratama, 2016:4)

Tabel 1

Format Penilaian

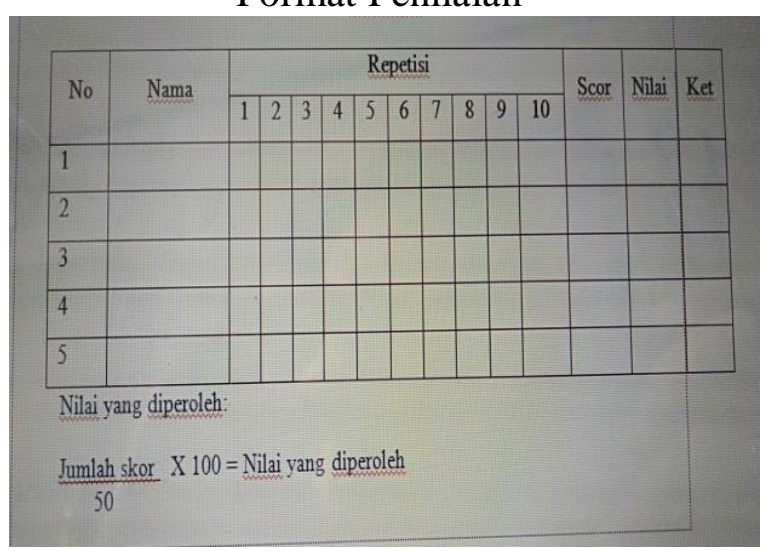

Dari hasil tes maka akan terkumpul data yang harus diolah dan dianalisis untuk mengelola data tersebut digunakan statistic deskriptif, sebagaimana diungkapkan Sugiyono (2017:207) "Statistik deskriptif adalah statistic yang digunakan untuk menganalisis data dengan cara mendeskripsikan atau menggambarkan data yang telah terkumpul sebagaimana adanya, penyajian data melalui table, grafik, penyebaran data melalui perhitungan rata-rata dan standar deviasi".

Sebelum melangkah ke uji-t ada persyaratan yang harus dipenuhi oleh peneliti bahwa data yang dianalisis harus berdistribusi normal. 
1) Nilai Rata - rata

Nilai rata-rata adalah suatu nilai yang akan mengembangkan mengenai kemampuan kelompok secara keseluruhan, (Nurhasan dan Cholil, 2014:399). Data yang telah terkumpul diolah dan ditentukan rata-rata hitungannya (mean), nilai mean dapat ditentukan dengan berbagai jumlah data dengan banyaknya data.

Rumus : $\overline{\boldsymbol{X}}=\frac{\sum \mathbf{x}}{\mathbf{n}}$

\section{2) Simpangan Baku}

Simpangan baku adalah ukuran penyebaran yang distandarisir yang bertolak dari nilai ratarata, (Nurhasan dan Cholil, 2014:399). Data yang telah terkumpul diolah dan ditentukan simpangan baku (Standars deviasi).

Rumus : $S=\sqrt{\frac{\sum(x-\bar{x})^{2}}{N-1}}$

Pengujian normalitas sebaran data menggunakanKolmogorov-Smirnov T Testdengan bantuan SPSS 16. Jika nilai p> dari 0,05 maka data normal, akan tetapi sebaliknya jika hasil analisis menunjukkan nilai $\mathrm{p}<$ dari 0,05 maka data tidak normal.

Uji homogenitas dilakukan dengan mengunakan uji anova test, jika hasil analisis menunjukkan nilai $\mathrm{p}>$ dari 0.05 , maka data tersebut homogen, akan tetapi jika hasil analisis data menunjukkan nilai $\mathrm{p}<$ dari 0.05, maka data tersebut tidak homogen.

Pengujian hipotesis menggunakan uji Paired Sampel T Testdengan bantuan program SPSS 16. Data dikatakan berpengaruh apabila signifikasinya lebih besar dari $5 \%$ atau 0,05

\section{Hasil dan Pembahasan}

Penelitian dilaksanakan tanggal 29 November-22 Desember 2018 di SMK Negeri 1 Lemahabang dengan 12 kali pertemuan, latihan dilaksanakan 3 (tiga) kali dalam seminggu yaitu hari Rabu, Jum'at, dan Sabtu pukul 15.30 - 17.00 dan 07.00 - 09.00 WIB. Hasil penelitian ini adalah data yang diperoleh dari tes awal dan tes akhir untuk meneliti pengaruh metode drill terhadap hasil smash siswa ekstrakulikuler permainan bulutangkis SMK Negeri 1 Lemahabang Kecamatan Lemahabang Kabupaten Cirebon dideskripsikan sebagai berikut:

Tabel 2

Descriptive Statistics

\begin{tabular}{|l|r|r|r|r|r|}
\hline & \multicolumn{1}{|l|}{ N } & Minimum & Maximum & Mean & Std. Deviation \\
\hline Pree Test Eksperimen & 20 & 30 & 46 & 36.80 & 4.420 \\
Post Test Eksperimen & 20 & 34 & 48 & 42.30 & 3.962 \\
Valid N (listwise) & 20 & & & & \\
\hline
\end{tabular}


Pada tes awal di peroleh data dari jumlah sampel sebanyak 20siswa adalah sebagai berikut rata-rata nilai hasil tes smash bulutangkis yaitu 36.80 dengan hasil terendah 30 dan hasil terbaik 46 dengan simpang baku 4.420 .

Pada tes akhir di peroleh data dari jumlah sampel sebanyak 20 orang adalah sebagai berikut rata-rata nilai hasil tes smash bulutangkis yaitu 42.30dengan hasil terendah 34 dan hasil terbaik 48 dengan simpang baku 3.962

Grafik 1

Peningkatan Metode Drill Hasil Smash Bulutangkis

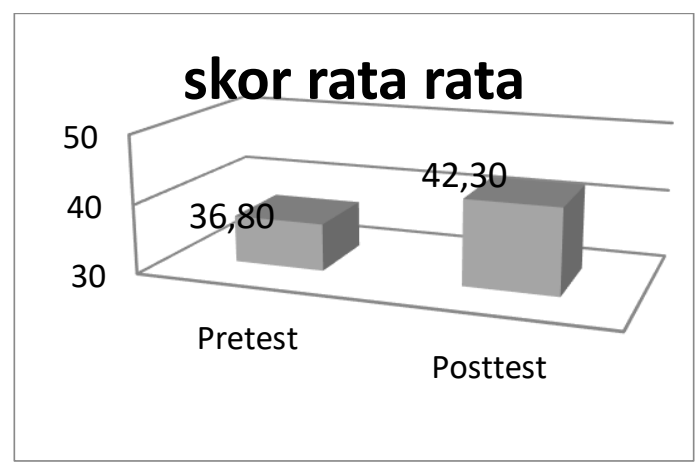

Berdasarkan grafik diatas terjadi peningkatan metode drill dari hasil tes awal dan tes akhir memiliki skor rata-rata diantaranya tes awal 36.80 dan tes akhir 42.30 berarti mengalami peningkatan 5.5.

Tabel 3

Tests Of Normality

\begin{tabular}{|c|c|c|c|c|c|c|c|}
\hline \multirow{3}{*}{$\begin{array}{l}\text { Hasil Belajar } \\
\text { Siswa }\end{array}$} & \multirow[t]{2}{*}{ Kelas } & \multicolumn{3}{|c|}{ Kolmogorov-Smirnov ${ }^{\mathrm{a}}$} & \multicolumn{3}{|c|}{ Shapiro-Wilk } \\
\hline & & Statistic & \begin{tabular}{|l|} 
\\
$\mathrm{f}$
\end{tabular} & Sig. & \begin{tabular}{|l|} 
Statisti \\
c
\end{tabular} & df & Sig. \\
\hline & $\begin{array}{l}\text { Preetest } \\
\text { Eksperimen } \\
\text { Postest } \\
\text { Eksperimen }\end{array}$ & .130 & 20 & $.200^{*}$ & .943 & $\begin{array}{l}2 \\
0 \\
2 \\
0\end{array}$ & .270 \\
\hline
\end{tabular}

Dari hasil diatas dapat dilihat bahwa semua data memiliki nilai $\mathrm{p}(\mathrm{Sig})>0.05$, maka variable distribusi normal.

Tabel 4

Test of Homogeneity of Variance

\begin{tabular}{|ll|r|r|r|r|}
\hline & Levene & & & \\
& & Statistic & df1 & df2 & \multicolumn{1}{l|}{ Sig. } \\
\hline Hasil & Based on Mean & .281 & 1 & 38 & .599 \\
Belajar & Based on Median & .131 & 1 & 38 & .719 \\
Siswa & Based on Median and with adjusted df & .131 & 1 & 36.900 & .719 \\
& Based on trimmed mean & .208 & 1 & 38 & .651 \\
\hline
\end{tabular}


Dari table 4 diatas dapat dilihat nilai $\mathrm{p}(\mathrm{Sig})>0.05$, sehingga data bersifat homogeny. Terdapat pengaruh metode drill terhadap hasil smash siswa ekstrakulikuler permainan bulutangkis SMK Negeri 1 Lemahabang Kecamatan Lemahabang Kabupaten Cirebon.

Tabel 5

Paired Sampel T Test

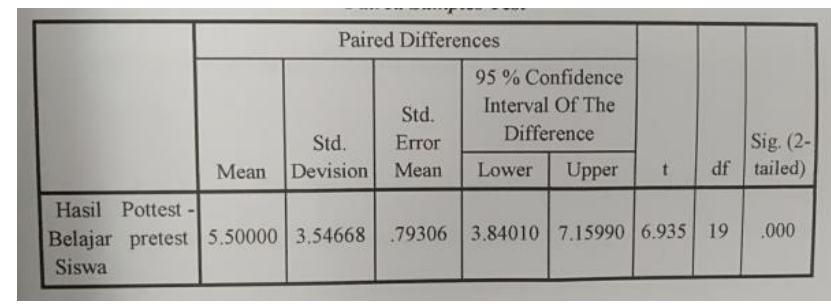

Karena nilai t hitung lebih besar dari t tabel (6.935> 2.093) maka Ho ditolak artinya Hi diterima, dengan kata bahwa terdapat perbedaan yang signifikan antara tes awal dan tes akhir.

Penelitian ini bertujuan untuk mengetahui hasil smash siswa ekstrakulikuler permainan bulutangkis SMK Negeri 1 Lemahabang Kecamatan Lemahabang Kabupaten Cirebon. Siswa yang diberikan metode drill lebih senang dan antusias dalam mengikuti proses pembelajaran selama beberapa waktu sampai siswa tersebut mencapai tujuan smash yang lebih baik. Setelah dilakukan penelitian hasil yang dicatat adalah angka yang dihasilkan siswa dalam melakukan tes preetest dan posttest smash sebanyak 10 kali melakukan, jika shuttlecock keluar dari lapangan atau tidak melewati net maka bernilai 0.Kemudian jumlah skor x 100 / 50 maka terdapat nilai yang diperoleh.

Hasil dari penghitungan data dengan menggunakan SPSS versi 16 maka diperoleh hasil skor rata-rata pada nilai pretest mendapatkan nilai minimal 30, nilai maksimal 46, rata-rata 36.80 dengan standar deviasi 4,420. Hal ini disebabkan oleh kurangnya variasi metode pembelajaran sehingga membuat kondisi siswa ekstrakulikuler kurang dalam melakukan teknik dasar smash bulutangkis. Setelah melaksanakan dengan metode drill hasil latihan siswa meningkat dengan hasil smash posttest didapat nilai minimal 34, nilai maksimal 48, rata-rata 42,30 dengan standar deviasi 3.962. Sehingga semua siswa melakukannya lebih semangat dan antusias dalam melakukan proses pembelajaran metode drill dan kemampuan yang dimiliki siswa pada gerak dasar smash dapat meningkatkan smash permainan bulutangkis. Berdasarkan hasil analisis data di peroleh nilai sig. 0.000 dan nilai t hitung 6.935. Dengan demikian hipotesis penelitian diterima.

Adanya peningkatan smash pada siswa karena metode drill smash bentuk latihannya dengan melakukan smash yang diulang-ulang dapat membiasakan siswa untuk melakukan 
gerakan smash, sehingga siswa merasa terbiasa atau semakin otomatisasi gerak. Pemberian metode drill pada setiap gerak akan mempercepat siswa dalam menguasai keterampilan gerak.

Metode drill dapat meningkatkan hasil smash hal ini sesuai dengan teori Connectionism oleh Thorndike yang dikutip oleh Suharno 1993 (dalam Wiratama, 2016:7), yang ada hubungannya dengan metode drill menyatakan bahwa "Dengan latihan yang terus menerus, hubungan antara rangsangan dan jawaban menjadi otomatis".

Penelitian ini diperkuat oleh hasil penelitian dari Wiratama (2016) dengan judul "Pengaruh Metode Latihan Drill Dan Pola Pukulan Terhadap Ketepatan Smash Atlet Bulutangkis Putra Usia 10-12 Tahun Di PB Jaya Raya Satria Yogyakarta”. Bahwa hasil peneltiannya ada pengaruh metode drill terhadap ketepatan smash atlet bulutangkis putra usia 10-12 tahun di PB Jaya Raya Satria Yogyakarta.

Dari uraian di atas bahwa metode drill memberikan pengaruh positif terhadap peningkatan hasil smash siswa yang mengikuti ekstrakulikuler permainan bulutangkis SMK Negeri 1 Lemahabang Kecamatan Lemahabang Kabupaten Cirebon. Metode drill yang dipelajari yaitu memberikan umpan servis panjang pada siswa dan siswa melakukan smash. Dengan gerakan yang diulang-ulang tentu dapat meningkatkan keinginan dan kemampuan siswa dalam teknik-teknik dasar gerakan smash secara menyeluruh dapat meningkatkan prestasi ekstrakulikuler bulutangkis disekolah.

\section{Kesimpulan}

Berdasarkanhasil perhitungan dan analisis data diperoleh kesimpulan sebagai berikut: "Terdapat pengaruh metode drill terhadap hasil smash siswa ekstrakulikuler permainan bulutangkis SMK Negeri 1 Lemahabang Kecamatan Lemahabang Kabupaten Cirebon”.

Berdasarkan hasil penelitian ini disarankan: Bagi siswa ekstrakulikuler permainan bulutangkis yang masih kurang dalam teknik dasar smash agar terus berusaha meningkatkan latihan, sehingga akan meningkatkan kemampuan dalam bermaian bulutangkis khususnya smash dan berhasil mencapai prestasi yang maksimal. Bagi guru atau pelatih agar selalu memperhatikan kemampuan anak dalam teknik dasar bulutangkis dengan memberikan pembelajaran berbagai metode latihan yang efektif yaitu metode drill dan metode-metode lainnya. Bagi peneliti selanjutnya hendak melakukan penelitian dengan metode yang berbeda, sehingga untuk meningkatkan hasil smash siswa ekstrakulikuler permainan bulutangkis dapat teridentifikasi lebih luas lagi. 


\section{Daftar Pustaka(11 pt)}

Amirulloh.(2014). Kepelatihan Dan Fisiologi Olahraga.

Arikunto, S. (2014). Prosedur Penelitian Suatu Pendekatan Praktek. Jakarta: Rineka Cipta.

Badriah, D. W.(2012).MetodePenelitian Ilmu - Ilmu Kesehatan, Bandung.

Budiwanto, S., Rahayuni, K. \& Sulistyorini. Peningkatan Keterampilan Teknik Dasar Pukulan Forehand Overhead Stroke Menggunakan Metode Latihan Berulang (Drilling) Umpan Lempar. Jurnal.Keolahragaan, volume VII, Nomor 1, Maret 2016, halaman 111-112.

Darmadi. (2017). Pengembangan Model Dan Metode Pembelajaran Dalam Dinamika Belajar Siswa. Yogyakarta: CV BUDI UTAMA.

Nugroho, A, J. (2015). Latihan Metode Drill untuk meningkatkan kemampuan Passing Atas Bola Voli Peserta Ekstrakulikuler Bola Voli Di SD Negeri Gento Windusasi Kabupaten Magelang. (Skripsi). Yogyakarta: FIK UNY. Halaman 9.

Nurhasan, H dan Cholil D. (2014). Modul Tes Dan Pengukuran Keolahragaan. Bandung:Fakultas Pendidikan Olahraga dan Kesehatan UPI.

Poole, J. (2013). Belajar Bulutangkis, Bandung: Pionir Jaya.

Prabowo, Y. A. (2015). Ketepatan Smash Bulutangkis Peserta Ekstrakulikuler Bulutangkis Putra Di SMP Negeri 13 Yogyakarta.Skripsi. Yogyakarta: FIK UNY. Halaman 11 - 15.

Rusman. (2007). Belajar Dan Pembelajaran Berorientasi Standar Proses Pendidikan. Jakarta: PT Kharisma Putra Utama.

Suardi, M. (2018). Belajar Dan Pembelajaran. Yogyakarta: CV BUDI UTAMA.

Subarjah, H, dan Hidayat, Y. (2007). Modul Permainan Bulutangkis. Bandung: Fakultas Pendidikan Olahraga dan Kesehatan UPI

Sugiono. (2017).Metode Penelitian Pendidikan, pendekatan Kuantitatif, Kualitataif, dan R\&D. Bandung: ALFABETA, cv.

Sugiyanto, F.X., \& Yuliawan, D. (2014). Pengaruh Metode Latihan Pukulan Dan Kelincahan Terhadap Keterampilan Bermain Bulutangkis Atlet Tingkat Pemula.Jurnal. Keolahragaan, Volume 2 Nomor 2,2014. Halaman 146.

Wakhid, M. (2016). Pengaruh Permainan Lempar Shutlecock Terhadap Peningkatan Kelincahan Peserta Ekstrakulikuler Bulutangkis SMP Negeri 2 Playen. Skripsi. Yogyakarta: FIK UNY.Halaman 7.

Wiratama, S. A. (2016). Pengaruh Metode Latihan Drill dan Pola Pukulan Terhadap Ketepatan Smash Atlet Bulutangkis Putra Usia 10 - 12 Tahun Di PB Jaya Raya Satria Yogyakarta. Jurnal. Keolahragaan, halaman 3 - 4.

Yanti N., Adawiah, R, \& Matnuh, H. (2016). Pelaksanaan Kgiatan Ekstrakulikuler Dalam Rangka Pengembangan Nilai-Nilai Karakter Siswa Untuk Menjadi Warga Negara Yang Baik Di SMA Korpri Banjarmasin. Jurnal Pendidikan Kewarganegaraan, Volume 6, Nomor 11, Mei 2016. Halaman 965.

Sumber - Sumber Lainnya:

http://id.wikipedia.org/wiki/2014/03/28/Bulu_tangkis

http://www.sarjanaku.com/2013/05/pengertian-metode-latihan-drill.html.Diunduh pada tanggal 02 Oktober 2018 pukul 20.13 wib.

http://master-bulutangkis.com Diunduh pada tanggal 02 Oktober 2018 pukul 13.12 wib. 